\title{
Acute Kidney Injury with Rhabdomyolysis: 25 Years Experience from a Tertiary Care Center
}

\author{
Rubina Naqvi*, F. Akhtar, E. Ahmed, A. Naqvi, A. Rizvi \\ Sindh Institute of Urology and Transplantation (SIUT), Karachi, Pakistan \\ Email: "rubinanaqvi@gmail.com
}

Received 15 June 2015; accepted 18 August 2015; published 21 August 2015

Copyright (C) 2015 by authors and Scientific Research Publishing Inc.

This work is licensed under the Creative Commons Attribution International License (CC BY). http://creativecommons.org/licenses/by/4.0/

(c) (i) Open Access

\section{Abstract}

Objective: To describe patients presenting with acute kidney injury after rhabdomyolysis at a tertiary renal care center in Pakistan. Patients and Methods: An observational cohort of patients identified as having acute kidney injury (AKI) with rhabdomyolysis, which was diagnosed by rise in creatinine phosphokinase (CK) and lactate dehydrogenase (LDH) more than 4 times the reference range whereas AKI was defined according to RIFLE criteria. On ultrasonography, all patients had normal size non obstructed kidneys, and no other co morbid. Results: Between January1990 to December 2014, 334 patients with rhabdomyolysis and AKI registered to this hospital. Mean age was 28.22 \pm 11.22 years with M:F ratio of 3.33:1. Mean values of CK and LDH were 597,749.790 \pm $180,461.360$ and $4077.026 \pm 5050.704 \mathrm{U} / \mathrm{L}$ with reference range of $26-174 \mathrm{U} / \mathrm{L}$ and $91-180 \mathrm{U} / \mathrm{L}$ respectively. We divided the study population into 4 groups over timeline. Rhabdomyolysis etiology was divided in 3 groups; 1) traumatic, 2) non-traumatic exertional, and 3) non-traumatic non-exertional. In the last group, which spans from 2010-2014, we treated many cases with toxic rhabdomyolysis and main toxin was paraphenylenediamine (PPD). The other causes showed more or less same prevalence over two and a half decade, except non-traymatic exertional which has decreased during last 5 years without any explainable cause. Renal replacement therapy (RRT) was required on arrival in $94 \%$ cases. Complete renal recovery was observed in $\mathbf{7 0 \%}$, while $15.86 \%$ died and $10 \%$ were lost during recovery phase. A small number $2.69 \%$ left against medical advice during acute phase of illness and $0.8 \%$ developed chronic kidney disease (CKD). Conclusion: The common clinical conditions found associated with rhabdomyolysis and AKI includes trauma, immobilization, sepsis, overexertion, and drugs and toxins. In recent years, we have seen many young patients with PPD poisoning; we have found good renal recovery in patients who survived initial 2 - 3 weeks.

\footnotetext{
${ }^{*}$ Corresponding author.
} 


\section{Keywords}

\section{Acute Kidney Injury, Rhabdomyolysis, RIFLE Criteria, Torture, Toxins, PPD}

\section{Introduction}

Rhabdomyolysis is a syndrome in which muscle pain and necrosis occurs with release of intracellular muscle constituents into the circulation. A variety of events can lead to rhabdomyolysis and this result in rise of Creatinine phosphokinase (CK) levels. Presence of myoglobinuria may or may not be observed. The Symptomatology ranges from simple moderate elevations in serum muscle enzymes to life-threatening disease associated with extreme enzyme elevations, electrolyte imbalances (especially hyperkalemia), and acute kidney injury [1].

The final common pathway for injury in rhabdomyolysis is an increase in intracellular free ionized cytoplasmic and mitochondrial calcium. This may be caused by depletion of adenosine triphosphate (ATP), the cellular source of energy, and/or by direct injury and rupture of the plasma membrane [2] [3].

ATP depletion causes dysfunction of the Na/K-ATPase and $\mathrm{Ca}^{2+}$ ATPase pumps that are essential for maintaining the integrity of the muscle cells, resulting in release of muscle enzymes in the circulation. The exact mechanism of myoglobin causing defective glomerular filtration is not known. Previous experimental and clinical studies suggest that intra renal vasoconstriction, direct tubular injury, indirect (ischemic) tubular injury and intra luminal blockade with myoglobin casts all can play a role [4].

New classification of causes of rhabdomyolysis categorizes broadly into three groups, that is: traumatic, nontraumatic exertional and non-traumatic non-exertional. Traumatic includes crush syndrome or prolonged immobilization. Non-traumatic exertional includes marked exertion in untrained individuals, recurrent convulsions, human stampede, hyperthermia, or metabolic myopathies. While non-traumatic non-exertional mainly drugs, toxins and infections [5]-[9].

Detailed history and clinical examination often provide a clue for the cause in an individual.

Many large series have been published in the past, reporting relative frequencies of different etiologies [4] [5] [10]. In the present study, we report AKI secondary to rhabdomyolysis from single tertiary care center, over a period of 25 years.

\section{Methods and Patients}

An observational cohort of patients identified as having AKI, which was defined according to RIFLE criteria [11], with normal size, non-obstructed kidneys, after rhabdomyolysis, which was defined as rise in CK and lactate dehydrogenase (LDH) more than 4 times the reference range. Study includes all patients with AKI secondary to rhabdomyolysis registered at this institution from January 1990 to December 2014.

For our laboratory, reference ranges for CK and LDH are 26 - 174 and 91 - 180 U/L respectively. All biochemical tests were done on Unicel DxC 800 Synchron Clinical System, Beckman Coulter auto-analyzer.

Myoglobinuria was checked with $\left(\mathrm{NH}_{4}\right)_{2} \cdot \mathrm{SO}_{4}$ method and markers for myoglobin were checked on pigment casts of histological samples. Renal biopsy was performed in 12 patients where history was dubious and patients reached late. For immunohistochemistry, tissue sections were immersed in peroxidase quenching solution and rinsed with PBS. Primary antibody (polyclonal rabbit anti human Myoglobin, Dako, Glostrup, Denmark) in dilution of 1:400 was applied for 30 - 60 minutes at room temperature followed by PBS rinsing. Secondary antibody (HRP: horse reddish peroxidase. Dako LSAB +/HRP kit, Dako, Glostrup, Denmark) was applied for 10 minutes at room temperature followed by PBS rinsing. Enzyme conjugate was applied for 10 minutes at room temperature followed by PBS rinsing. Chromogen substance (DAB, Dako, Glostrup, Denmark) was applied for 5 - 10 minutes followed by PBS rinsing and light counter stain with Hematoxylin and mounting of slides. The slides were visualized under the light microscope.

The patients who remained on follow up; which expands from first discharge to maximum of 23 years, and not recovered normal renal functions but remain dialysis free were labeled as CKD.

We divided the population in 4 time periods, for observing any change in trends in different causes of rhabdomyolysis. Whereas, rhabdomyolysis was divided in 3 groups based on etiology: Traumatic, which include crush syndrome and prolonged immobilization, torture causing blunt trauma, burn, and electrocution; non- 
traumatic exertional include prolonged exercises by untrained personnel and prolonged convulsions, whereas; non-traumatic non-exertional include drugs, toxins, and infections. Quantitative variables reported as means \pm STD and Qualitative as percentages.

\section{Results}

A total of 5623 patients with AKI brought to this hospital between January 1990 to December 2014, of these 334 (5.9\%) were secondary to rhabdomyolysis. Average age of patients in this group was $28.22 \pm 11.29$ years, 258 were male and 76 were females.

Traumatic rhabdomyolysis include 28 patients from road traffic accidents, 24 from crush injury (earthquake, collapsed roof and fire arm injuries), prolonged immobilization, electrocution, blunt trauma, burn and 58 cases of torture. Last group includes person beaten up by batons, fists, leather belts, hanging upside down and sits ups given for torture purpose (Table 1).

Non traumatic exertional group includes 30 people with prolonged exercise in untrained people, especially in hot weather and 23 epileptic patients brought after status epilepticus (Table 1).

Non traumatic non exertional group include infections and poisonings with drugs, substances or venom (Table 1).

During different time periods that is initial 10 years, then 5 years, 5 years and 5 years, prevalence of traumatic rhabdomyolysis remains unchanged, non traumatic exertional shown decline during last 5 years, while the last group of non traumatic non exertional rhabdomyolysis has shown dramatic increase of PPD poisoning during last 5 years (Table 2).

The main demographic, clinical and laboratory parameters of the study population are given in Table 3. Majority patients were young; males were 3.3 times more than females. Majority was in advanced uremia and muscle enzymes were many folds higher than reference range (Table 3).

Renal biopsy was done in 12 cases and revealed acute tubular necrosis in all with presence of pigment casts in tubular lumina in 8 cases. Immunohistochemistry for myoglobin was positive in these patients.

The complete recovery from AKI was seen in 70\% of patients, highest observed in non-traumatic exertional rhabdomyolysis (83\%). Mortality was high in traumatic rhabdomyolysis (22.22\%), among these crush injury

Table 1. Causes of rhabdomyolysis $(\mathrm{N}=334)$.

\begin{tabular}{ccc}
\hline Traumatic $=\mathbf{1 2 6}$ & Non Traumatic exertional $=\mathbf{5 3}$ & Non traumatic, non-exertional $=\mathbf{1 5 5}$ \\
\hline RTA $=28$ & Poison PPD $=75$ \\
Crush injury $=24$ & Prolonged exercise $=30$ & Alcohol binge $=10$ \\
(Including fire arm injury $=11)$ & Marihuana Binge $=9$ \\
Prolonged immobilization $=3$ & Recurrent Convulsions $=23$ & Infections $=35$ \\
Electrocution $=3$ & Scorpion venom $=5$ \\
Burn $=1$ & Snake venom $=5$ \\
Blunt trauma $=9$ & Drugs over dosage $=4$ \\
Torture $^{*}=58$ & Others $=12$ \\
\hline
\end{tabular}

*Torture cases include beaten up by batons, fists, leather belts, hanging upside down, sit-ups.

Table 2. Pattern over different time periods.

\begin{tabular}{cccccc}
\hline $\begin{array}{c}\text { Cause of } \\
\text { Rhabdomyolysis }\end{array}$ & $\begin{array}{c}1990-1999 \\
(\mathrm{n}=67)\end{array}$ & $\begin{array}{c}2000-2004 \\
(\mathrm{n}=35)\end{array}$ & $\begin{array}{c}2005-2009 \\
(\mathrm{n}=52)\end{array}$ & $\begin{array}{c}2010-2014 \\
(\mathrm{n}=180)\end{array}$ & $\begin{array}{c}\text { Total } 25 \text { yrs } \\
(\mathrm{n}=334)\end{array}$ \\
\hline $\begin{array}{c}\text { Traumatic } \\
\begin{array}{c}\text { Non-traumatic } \\
\text { exertional }\end{array}\end{array}$ & $42(62)$ & $20(57)$ & $32(62)$ & $32(18)$ & $126(37.72)$ \\
$\begin{array}{c}\text { Non-traumatic } \\
\text { non-exertional }\end{array}$ & $21(31)$ & $10(28)$ & $13(52)$ & $9(5)$ & $53(15.86)$ \\
\hline
\end{tabular}

\footnotetext{
\% $\%$ in parenthesis.
} 
was worst which revealed $45.83 \%$ mortality as subgroup. For non-traumatic non-exertional group, overall mortality was $12.9 \%$ with infection contributing most (14.28\%). The poisoning with PPD, which comprises largest of this last group, showed mortality of 6.6\% (Table 4). Fifty three patients died during acute phase of illness, 26 of these within 24 hours of reaching to hospital. Multi organ failure, sepsis and recurrent hyperkalemia were main causes of mortality in the study population (Table 5).

Table 3. Demography and laboratory values $(\mathrm{N}=334)$.

\begin{tabular}{cc} 
M:F & $3.3: 1$ \\
Age mean \pm SD, years & $28.221 \pm 11.299$ \\
Duration of insult mean \pm SD, days & $7.346 \pm 5.510$ \\
Hb mean \pm SD, g/dl & $11.300 \pm 2.496$ \\
Blood Urea mean \pm SD, mg/l & $265.895 \pm 109.411$ \\
Serum Creatinine mean \pm SD, mg/l & $12.142 \pm 5.550$ \\
LDH mean \pm SD, U/l & $4077.026 \pm 5050.704$ \\
CK mean \pm SD, U/l & $59,774.790 \pm 180,461.356$ \\
AST mean \pm SD, U/l & $1954.298 \pm 2397.769$ \\
ALT mean \pm SD, U/l & $888.95 \pm 1100.987$ \\
\hline
\end{tabular}

Table 4. Outcome in different groups $(\mathrm{N}=334)$.

\begin{tabular}{|c|c|c|c|c|c|}
\hline Cause & Complete recovery & Partial recovery $^{* *}$ & LAMA ${ }^{*}$ & ESRF & Died \\
\hline Traumatic = 126 & $=84$ & $=10$ & $=04$ & & $=28$ \\
\hline - $\quad \mathrm{RTA}=28$ & 15 & 3 & $\mathbf{0}$ & & 10 \\
\hline - $\quad$ Crush injury $=24$ & 10 & 2 & 1 & & 11 \\
\hline - $\quad$ Prolonged immobilization $=3$ & 3 & $\mathbf{0}$ & & & $\mathbf{0}$ \\
\hline - $\quad$ Electrocution $=3$ & 1 & 1 & & & 1 \\
\hline - $\operatorname{Burn}=1$ & 1 & $\mathbf{0}$ & & & $\mathbf{0}$ \\
\hline - $\quad$ Other trauma $=9$ & 6 & $\mathbf{0}$ & & & 3 \\
\hline - $\quad$ Torture $=58$ & 48 & 4 & 3 & & 3 \\
\hline Non traumatic Exertional = 53 & $=44$ & $=02$ & $=00$ & $=01$ & $=06$ \\
\hline - $\quad$ Prolonged exercise $=30$ & 28 & 1 & $\mathbf{0}$ & $\mathbf{0}$ & 1 \\
\hline - $\quad$ Recurrent convulsion $=23$ & 16 & 1 & $\mathbf{0}$ & 1 & 5 \\
\hline Non traumatic non exertional = 155 & $=107$ & $=22$ & $=05$ & $=10$ & $=\mathbf{2 0}$ \\
\hline - $\quad$ Poison PPD = 75 & 65 & 3 & 2 & $\mathbf{0}$ & 5 \\
\hline - $\quad$ Alcohol binge = 10 & 4 & 5 & $\mathbf{0}$ & $\mathbf{0}$ & 1 \\
\hline - $\quad$ Marihuana binge $=9$ & 2 & 5 & $\mathbf{0}$ & 1 & 2 \\
\hline - $\quad$ Infections $=35$ & 21 & 5 & 3 & $\mathbf{0}$ & 5 \\
\hline - $\quad$ Scorpion bite $=5$ & 5 & $\mathbf{0}$ & $\mathbf{0}$ & $\mathbf{0}$ & $\mathbf{0}$ \\
\hline - $\quad$ Snake bite $=5$ & 5 & $\mathbf{0}$ & $\mathbf{0}$ & $\mathbf{0}$ & $\mathbf{0}$ \\
\hline - $\quad$ Drug over dose $=4$ & 3 & 1 & $\mathbf{0}$ & $\mathbf{0}$ & $\mathbf{0}$ \\
\hline - $\quad$ Others $=12$ & 2 & 3 & $\mathbf{0}$ & & 7 \\
\hline
\end{tabular}

*LAMA: refused treatment and left against medical advice, ${ }^{* *}$ Partial recovery: trends were towards improvement but didn’t turn up for follow up.

Table 5. Cause of death $(\mathrm{N}=53)$.

\begin{tabular}{ccc}
\hline Cause & No. & $\%$ \\
\hline MOF $^{*}$ & 17 & 32.07 \\
Sepsis & 29 & 54.71 \\
Hyperkalemia & 6 & 11.32 \\
G I bleed & 1 & 1.88 \\
\hline
\end{tabular}

${ }^{*}$ Respiratory, circulatory and coagulation along with AKI. 26/53 deaths occurred within first 24 hours of reaching this hospital. 


\section{Discussion}

Rhabdomyolysis has been described for thousands and thousands of years. Old Testament describes rhabdomyolysis in Israelites who consumed quail fed on hemlock [12]. Hemlock poison, also famous to execute Socrates, can cause rhabdomyolysis and acute tubular necrosis (ATN) along with other neurologic symptoms. During spring season, birds consume large amount of buds from plant and when eaten up by humans, toxins disintegrate and cause harm [13].

Musculoskeletal trauma, in particular crush syndrome, accounts for a large proportion of the cases of rhabdomyolysis. Initial reports are from 1908 during Sicilian earthquake in Messina where rescuers searched through the rubble for weeks, and whole families were still being pulled out alive, and later in timeline from German military literature and during the bombing of London in Second World War. Pigmented casts were found in the renal tubules at autopsy; however, at that time pathogenesis was unclear [14] [15].

Additional cases were described during the Korean War [16]. The decreased incidence of posttraumatic AKI during the Vietnam War could be explained on the basis of the faster evacuation techniques and improved fluid resuscitation of affected people [17].

According to previously published studies about $10 \%$ - 50\% of patients with rhabdomyolysis develop AKI [18]. Whereas with extensive traumatic injuries figure rises up to 85\%. Mortality for such patients, i.e. severe trauma, rhabdomyolysis and AKI, has been reported up to 20\% [19], more so with multi-organ dysfunction syndrome [20].

Rhabdomyolysis and crush syndrome are common results of natural disasters such as earthquakes. Many reports have been published on survivors of earthquakes who suffered from crush injury and AKI [21] [22]. In the present cohort, 10 patients were from earthquake of 2005 in northern area of country [23].

Rhabdomyolysis may complicate a high-voltage electrical injury and lightning strikes. It has been reported in $10 \%$ of subjects that survive an electrical shock. The clinical course following an electrical burn is similar to that of a crush injury. Pathogenesis can be ascribed to the electrical disruption of sarcolemmal membranes, with loss of barrier function and massive calcium influx [24] [25].

Non-traumatic myoglobinuria with AKI is a relatively common disease easy to diagnose and has an excellent prognosis [26]. Risk factors for non-traumatic rhabdomyolysis, include malignant hyperpyrexia, malignant neuroleptic syndrome, extreme exertion, recurrent seizures, bacterial and viral infections, use of certain medications, and exercise by untrained personnel especially in hot and humid weather [27]. In our study, we found 15.86\% patients with history of prolonged exercise or recurrent convulsions, while $10.47 \%$ had infection, and another $27.24 \%$ were affected by different toxins. To our surprise number of patients developing rhabdomyolysis after prolonged exercise has markedly decreased during last five years of study for which we have no proper explanation.

Myoglobinuria can be estimated by chemical methods, spectrophotometry and immunologic (radial immunodiffusion, complement fixation, counter immunoelectrophoresis) methods in laboratory [28]. Most simple, "sideroom" method, is to collect $5 \mathrm{ml}$ of urine, mix well with $2.8 \mathrm{gm}$ of $\left(\mathrm{NH}_{4}\right)_{2} \cdot \mathrm{SO}_{4}$, allow to stand for 5 minutes and then filter, colored supernatant indicates myoglobinuria while colored precipitate hemoglobinuria [27]. Important to mention is the fact that absence of myoglobinuria does not exclude the diagnosis [5].

Non-traumatic rhabdomyolysis has also been reported with alcohol intake, where the cause is not fully understood. The patho-physiology can be quite different between short- and long-term alcohol abuses [29]. Under short-term alcohol intoxication, immobilization or coma induced by ethanol-related central nervous system sedation plays an important role in developing rhabdomyolysis. It causes muscle compression and ischemia, which will accelerate short-term alcohol myotoxicity [30], resulting in a massive breakdown of skeletal muscle over a short period of time.

In long-term alcohol abuse, electrolyte abnormalities (i.e., hypokalemia, hypophosphatemia, or hypomagnesaemia) may play significant causative roles for developing rhabdomyolysis [29] [31].

There is a long list of medications and recreational drugs that can cause rhabdomyolysis by different mechanisms. Any drug that directly or indirectly impairs the production or use of ATP by skeletal muscle, or increases energy requirements that exceed the rate of ATP production, can cause rhabdomyolysis [32].

Heavy metals, insects venoms and snake venom (especially Sea-Snake and Elapids), have been reported to cause rhabdomyolysis [33]-[36]. Scorpion venom has rarely been reported as direct nephrotoxic agent [37] but extensive muscle necrosis at the site of sting which was observed in our studied population as well as reported 
previously, can give rise to muscle damage severe enough to cause tubular injury with myoglobin. Hemolytic uremic syndrome (HUS) has been reported after scorpion sting as a single case report in literature. [38] [39]

Another toxin, paraphenylenediamine (PPD) has been described as a hair dye since the end of $19^{\text {th }}$ century. Up till now, it is reported to be used in more than 1000 oxidative hair-dyes in the USA [40] [41]. PPD is also used in the photographic or rubber industries. In addition, in many African countries, PPD in its pure form or in combination with other natural coloring extracts like Henna, is used for coloring of palms and soles for cosmetic reasons [42] [43]. Unfortunately, there are also vast numbers of unintended and intended incidents of severe to life threatening intoxication involving this synthetic compound [43] [44]. PPD intoxication leads to a severe clinical syndrome including laryngeal edema, rhabdomyolysis and subsequent renal failure, neurotoxicity and acute toxic hepatitis which per se can lead to dark colored urine [44]. In our experience, we have started registering the rhabdomyolysis after intoxication with PPD mainly over last two years, though reports from India and Africa as case reports or case series are there in literature [44]-[46]. In the present study, majority were young females and ingested it as an attempt for committing suicide, as the substance is easily available widely at a low cost. A case series published from India reported complete renal recovery in 61.35\% of patients with PPD intoxication, but patient population was small with total cases of 13 in this particular study [44]. In our observation complete renal recovery was seen in $86.66 \%$ of PPD intoxication patients Rhabdomyolysis in association with crush injury has been reported with poor prognosis about seven decades ago [15], but with passage of time as understanding of patho-physiology improved and early methods of resuscitation adopted in large catastrophic situations, mortality rate has declined [22]. In the present study, mortality was $46 \%$ in crush injury victims but half of these succumbed to death within 24 hours of arrival to this hospital, indicating extent of insult and delay in reaching to this particular tertiary care service and poor infra structure of health facilities in country.

\section{Conclusion}

This study was conducted over a span of two and a half decades; we have observed changes in the pattern of causes of rhabdomyolysis. During the first decade, torture and blunt trauma was more common while during last five years largest contributing factor was toxic rhabdomyolysis with PPD ingestion. Patients who survived initial period of insult show good renal recovery. Mortality is mostly contributed by multi organ failure and sepsis. Remarkable number of deaths occurred soon after arrival highlighting the need of good supportive, well equipped infra structure at national level.

\section{Conflict of Interest}

None.

\section{References}

[1] Miller, M.L. (2014) Clinical Manifestations and Diagnosis of Rhabdomyolysis. Up Todate, Version 11.0.

[2] Giannoglou, G.D., Chatzizisis, Y.S. and Misirli, G. (2007) The Syndrome of Rhabdomyolysis: Pathophysiology and Diagnosis. European Journal of Internal Medicine, 18, 90. http://dx.doi.org/10.1016/j.ejim.2006.09.020

[3] Khan, F.Y. (2009) Rhabdomyolysis: A Review of the Literature. Netherlands Journal of Medicine, 67, 272.

[4] Bosch, X., Poch, E. and Grau, J.M. (2009) Rhabdomyolysis and Acute Kidney Injury. New England Journal of Medicine, 361, 62-72. http://dx.doi.org/10.1056/NEJMra0801327

[5] Gabow, P.A., Kaehny, W.D. and Kelleher, S.P. (1982) The Spectrum of Rhabdomyolysis. Medicine (Baltimore), 61, 141-152. http://dx.doi.org/10.1097/00005792-198205000-00002

[6] Melli, G., Chaudhry, V. and Cornblath, D.R. (2005) Rhabdomyolysis: An Evaluation of 475 Hospitalized Patients. Medicine (Baltimore), 84, 377. http://dx.doi.org/10.1097/01.md.0000188565.48918.41

[7] Huerta-Alardín, A.L., Varon, J. and Marik, P.E. (2005) Bench-to-Bedside Review: Rhabdomyolysis-An Overview for Clinicians. Critical Care, 9, 158. http://dx.doi.org/10.1186/cc2978

[8] Petejova, N. and Martinek, A. (2014) Acute Kidney Injury Due to Rhabdomyolysis and Renal Replacement Therapy: A Critical Review. Critical Care, 18, 224-231. http://dx.doi.org/10.1186/cc13897

[9] Sheikh, I.A., Shaheen, F.A.M., El Aqeil, N., Alkhader, A. and Karsuwa, S. (1994) ARF Due to Rhabdomyolysis Following Human Setmpede. Saudi Journal of Kidney Diseases and Transplantation, 5, 17-22.

[10] McMahon, G.M., Zeng, X. and Waikar, S.S. (2013) A Risk Prediction Score for Kidney Failure or Mortality in Rhab- 
domyolysis. JAMA Internal Medicine, 173, 1821. http://dx.doi.org/10.1001/jamainternmed.2013.9774

[11] Lameire, N., Van Biesen, W. and Vanholder, R. (2006) Acute Renal Failure. The Lancet, 365, 417-430. http://dx.doi.org/10.1016/S0140-6736(05)70238-5

[12] Book of Numbers: The Bible. The New English Bible (1970) Joint Comitee on the New Translation of the Bible. Cambridge University Press, New York, Vol. 11, 31-35.

[13] Rizzi, D., Basile, C. and Di Maggio, A. (1991) Clinical Spectrum of Accidental Hemlock Poisoning: Neurologic Manifestations, Rhabdomyolysis and Acute Tubular Necrosis. Nephrology Dialysis Transplantation, 6, 939-943. http://dx.doi.org/10.1093/ndt/6.12.939

[14] Vanholder, R., Sever, M.S., Erek, E. and Lameire, N. (2000) Rhabdomyolysis. Disease of the Month. Journal of the American Society of Nephrology, 11, 1553-1561.

[15] Bywaters, E.G.L. and Beall, D. (1941) Crush Injuries with Impairment of Renal Function. British Medical Journal, 1, 427-432. http://dx.doi.org/10.1136/bmj.1.4185.427

[16] Smith, L., Post, R., Teschan, P., Abernathy, R., Davis, J., Gray, D., Howard, J., Johnson, K., Klopp, E., Mundy, R., et al. (1955) Postraumatic Renal Insufficiency in Military Casualties. II Management, Use of an Artificial Kidney, Prognosis. American Journal of Medicine, 18, 187-198. http://dx.doi.org/10.1016/0002-9343(55)90234-5

[17] Stone, W. and Knepshield, J. (1974) Post Traumatic Acute Renal Insufficiency in Vietnam. Clinical Nephrology, 2, 189-190.

[18] Ward, M. (1988) Factors Predictive of Acute Renal Failure in Rhabdomyolysis. Archives of Internal Medicine, 148, 1553-1557. http://dx.doi.org/10.1001/archinte.1988.00380070059015

[19] Mohaupt, M. (2003) Rhabdomyolysis. Therapeutische Umschau, 60, 391-397. http://dx.doi.org/10.1024/0040-5930.60.7.391

[20] Splendiani, G., Mazzarella, V., Cipriani, S., Zazzaro, D. and Casciani, C. (2001) Dialytic Treatment of Rhabdomyolysis-Induced Acute Renal Failure: Our Experience. Renal failure, 23, 183-191. http://dx.doi.org/10.1081/JDI-100103490

[21] Sever, M., Erek, E., Vanholder, R., Akoglu, E., Yavaz, M., Ergin, H., Tekce, M., Korular, D., Tulbek, M., Keven, K., et al. (2001) The Marmara Earthquake: Epidemiological Analysis of the Victims with Nephrological Problems. Kidney International, 60, 1114-1123. http://dx.doi.org/10.1046/j.1523-1755.2001.0600031114.x

[22] Kantarci, G., Vanholder, R., Tuclular, S., Akin, H., Koc, M., Ozrner, C. and Akoglu, E. (2002) Acute Renal Failure Due to Crush Syndrome during Marmara Earthquake. American Journal of Kidney Diseases, 40, 682-689. http://dx.doi.org/10.1053/ajkd.2002.35673

[23] Van Dam, R. (2006) Earthquake in Pakistan-The Renal Disaster Relief Task Force in Action. EDTNA-ERCA Journal, 32, 104-107. http://dx.doi.org/10.1111/j.1755-6686.2006.tb00461.x

[24] Rosen, C., Adler, J., Rabban, J., Sethi, R., Arkoff, L., Blair, J. and Sheridan, R. (1999) Early Predictors of Myoglobinuria and Acute Renal Failure Following Electrical Injury. The Journal of Emergency Medicine, 17, 783-789. http://dx.doi.org/10.1016/S0736-4679(99)00084-0

[25] Brumback, R., Feeback, D. and Leech, R. (1995) Rhabdomyolysis Following Electrical Injury. Seminars in Neurology, 15, 329-334 http://dx.doi.org/10.1055/s-2008-1041040

[26] Grossman, R.A., Hamilton, R.W., Morse, B.M., Penn, A.S. and Goldberg, M. (1974) Nontraumatic Rhabdomyolysis and Acute Renal Failure. The New England Journal of Medicine, 291, 807-811.

[27] Sweny, P. (1989) Pigment Nephropathy: Rhabdomyolysis and Hemolysis. In: Sweny, P., Farrington, K. and Morehead, J.F. Eds., The Kidney and Its Disorders, Chapter 22, Blackwell Scientific Publications, Oxford, 348-358.

[28] Markowitz, H. and Wobing, G.H. (1977) Quantitative Methods for Estimating Myoglobin in Urine. Clinical Chemistry, 23, 1689-1693.

[29] Haller, R.G. and Knochel, J.P. (1984) Skeletal Muscle Disease in Alcoholism. Medical Clinics of North America, 68, 91-103.

[30] Song, S.K. and Rubin, E. (1972) Ethanol Produces Muscle Damage in Human Volunteers. Science, 175, $327-328$. http://dx.doi.org/10.1126/science.175.4019.327

[31] Knochel, J.P. (1992) Hypophosphatemia and Rhabdomyolysis. American Journal of Medicine, 92, 455-457. http://dx.doi.org/10.1016/0002-9343(92)90739-X

[32] Kakulas, B. (1981) Experimental Myopathies. In: Walton, S.J., Ed., Disorders of Voluntary Muscle, Churchill Livingstone, New York, 393-400.

[33] Sitprija, V., Gopalakrishnakone, P. and Martinez-Maldonado, M. (1998) Snake Bite, Rhabdomyolysis, and Renal Failure. American Journal of Kidney Diseases, 31, l-lii. http://dx.doi.org/10.1016/S0272-6386(14)70010-1 
[34] Chugh, K.S. (1989) Snake Bite Induced ARF in India. Kidney International, 35, 891-907.

[35] Gold, B.S., Dart, R.C. and Barish, R.A. (2002) Bites of Venoumous Snakes. The New England Journal of Medicine, 347, 346-56. http://dx.doi.org/10.1056/NEJMra013477

[36] Reid, H.A. (1961) Myoglobinuria and Sea Snake Bite Poisoning. British Medical Journal, 1, 1284-1289.

[37] Naqvi, R., Naqvi, A., Akhtar, F. and Rizvi, A. (1998) ARF Developing after a Scorpion Sting. British Journal of Urology, 82, 295.

[38] Mocan, H., Mocan, M.Z. and Kaynar, K. (1998) HUS Following a Scorpion Sting. Nephrology Dialysis Transplantation, 13, 2639-2640.

[39] Valavi, E., Ansari, M.J.A. and Hoseini, S. (2011) ADAMTS-13 Deficiency Following Scorpion Sting. Saudi Journal of Kidney Diseases and Transplantation, 22, 792-795.

[40] Dressler, W.E. and Appelqvist, T. (2006) Plasma/Blood Pharmacokinetics and Metabolism after Dermal Exposure to Para-Aminophenol or Para-Phenylenediamine. Food and Chemical Toxicology, 44, 371-379. http://dx.doi.org/10.1016/j.fct.2005.08.009

[41] Stanley, L.A., Skare, J.A., Doyle, E., Powrie, R., D’Angelo, D., et al. (2005) Lack of Evidence for Metabolism of p-Phenylenediamine by Human Hepatic Cytochrome P450 Enzymes. Toxicology, 210, 147-157. http://dx.doi.org/10.1016/j.tox.2005.01.019

[42] Meyer, A., Blomeke, B. and Fischer, K. (2009) Determination of p-Phenylenediamine and Its Metabolites MAPPD and DAPPD in Biological Samples Using HPLC-DAD and Amperometric Detection. Journal of Chromatography B, 877, 1627-1633. http://dx.doi.org/10.1016/j.jchromb.2009.04.008

[43] Shalaby, S.A., Elmasry, M.K., Abd-Elrahman, A.E., Abd-Elkarim, M.A. and Abd-Elhaleem, Z.A. (2010) Clinical Profile of Acute Paraphenylenediamine Intoxication in Egypt. Toxicology and Industrial Health, 26, 81-87. http://dx.doi.org/10.1177/0748233709360200

[44] Chrispal, A., Begum, A., Ramya, I. and Zachariah, A. (2010) Hair Dye Poisoning-An Emerging Problem in the Tropics: An Experience from a Tertiary Care Hospital in South India. Tropical Doctor, 40, 100-103. http://dx.doi.org/10.1258/td.2010.090367

[45] Nagaraja, B.S., Spoorthy, S.S. and Mubarak, H. (2012) Hair Dye Poisoning: Case Report. International Journal of Clinical Cases and Investigations, 4, 43-48.

[46] Fatihi, E.M., Ramdani, B., Benghanem, M.G., Hachim, K. and Zaid, D. (1997) Rhabdomyolysis and Acute Renal Failure Secondary to Toxic Material Abuse in Morocco. Saudi Journal of Kidney Diseases and Transplantation, 8, 131133. 